\title{
Museo-Edificio: una relación con nuevas perspectivas
}

Rafael Alas Vásquez.

En los últimos años el tema del museo y su edificio ha ganado una gran notoriedad. Desde tiempos muy antiguos, los términos museo y edificio han estado íntimamente ligados. El término museo utilizado por los griegos ya viene asociado a la idea del edificio con el significado de "templo de las musas". En los templos de esta cultura se guardaba el "tesoro" del dios, constituido por preciosos objetos y vestuario de la deidad. Hay que recordar que el templo cristiano, desde los primeros tiempos, comienza también a acumular en su interior valiosos objetos artísticos, hecho que sobresale en la Edad Media, ya que dentro de las grandes catedrales ocupaban un lugar destacado las piezas artísticas que por su valor no estaban accesibles al público.

Sin embargo, pasará mucho tiempo para que estos objetos artísticos, y los que se acumulaban en palacios y casas nobiliarias, pasaran a la esfera de las colecciones públicas: el museo como institución para la población tardaría en aparecer. Cierta apertura de las colecciones privadas, en manos de la Iglesia o de la nobleza, se comenzó a dar a partir del Renacimiento (siglo XVI) cuando se abren las puertas de los recintos en donde se almacenaban las obras a intelectuales y artistas. Es así como las colecciones papales fueron visitadas por Miguel Ángel Buonarroti y otros pintores y escultores con el fin de estudiar los importantes ejemplos de la estatuaria griega y romana.

No es sino hasta el siglo XVIII cuando comienzan a aparecer los "grandes" museos de arte con apertura a la población. El Museo del Louvre (Francia) surge en 1791 con el germen de sus colecciones en las obras artísticas acumuladas por los reyes franceses durante muchos años. En este caso se recurre a un edificio existente, el antiguo palacio real de París, para albergar la gran cantidad de obras que se mostraría al público. 
El Museo del Prado en España tardaría en aparecer, siempre con una colección de gran importancia a partir de los tesoros acumulados por los reyes de la Casa Austria y los Borbones durante sus estadías en el poder. Pero el caso del museo madrileño es distinto, ya que por voluntad real se proyecta y se construye un edificio -inaugurado en 1819- para depositar estas colecciones las cuales no pertenecían exclusivamente al campo artístico. Estamos ante el caso de un edificio concebido para mostrar piezas de valor científico y artístico, proyectado por Juan de Villanueva por encargo del rey Carlos III, utilizando en su diseño elementos de la antigua arquitectura clásica: el mausoleo circular, la basílica con ábside y el templo porticado (El Museo del Prado de Madrid y sus pinturas, 1973).

En años sucesivos, se establecieron otros museos importantes con espacios como los dos casos anteriores: edificios diseñados y construidos para la exhibición de piezas y edificios adaptados y remodelados para este uso. Este impulso en cuanto al museo como institución pública llegaría al Nuevo Continente: el Museo Metropolitano de Nueva York fue abierto en 1870.

La existencia o no de un edificio como elemento esencial de un museo (y específicamente dentro del campo del arte) parece ser parte de la discusión actual, ante la tendencia de construir edificios emblemáticos y de formas atractivas para el usuario, constituyéndose en significativas obras arquitectónicas que junto con sus servicios son capaces de propiciar un desarrollo a las localidades donde son construidas. Tal ha sido el caso del Museo Guggenheim de Bilbao y de otros que se han edificado después con el criterio de que el envolvente de las colecciones debe constituirse en una obra artística más, capaz de atraer a nuevos públicos pero también a ser polos de desarrollo.

Este fenómeno ha generado discusiones y posiciones encontradas. Lucía Iglesias, en su publicación Bilbao: el efecto "Guggenheim”, cita a la escritora e ilustradora Asun Balzola, quien habla acerca de su ciudad natal Bilbao y del cambio en ella a raíz de la construcción del edificio del museo en su reciente libro Txoriburu (Cabeza de chorlito): "Lo más esperanzador es que los jóvenes son sus primeros fans. Cuando estás dentro del edificio, la luz, las espirales de su arquitectura hacen que casi dé igual lo que haya dentro, casi se podría visitar aunque estuviera vacío".

El director de este museo, Juan Ignacio Vidarte, se defiende ante las críticas con respecto a la preponderancia del edificio, argumentando: "Yo creo que es 
uno de los pocos museos del mundo en los que se pueden ver obras de escala monumental como las que realizan artistas contemporáneos como Richard Serra junto a obras de un tamaño mucho más íntimo, mucho más reducido como dibujos de Chillida o Giacometti” (www.news.bbc.co.uk).

Frente a esto, el artículo de Ann Wilson Lloyd, "Museos de arte pierden piso para el arte" (The New York Times, 2004) es altamente significativo al comentar la problemática del edificio vanguardista del Museo de Arte de Bellevue, Washington, diseñado con galerías que no eran propicias a la exhibición de obras de arte tradicionales, siendo esto uno de los factores para su cierre, de acuerdo con esta nota periodística. Haciendo referencia al "efecto Bilbao", el edificio en mención forma parte de esa tendencia a crear destacables volúmenes arquitectónicos que pueden dejar en segundo plano la función de exhibir obras, ya sea de valor artístico o antropológico.

Es inevitable que, cuando hablamos de museo, siempre nos viene a la mente la idea de un edificio. Sin embargo, la definición de museo aportada por el Icom (Consejo Internacional de Museos) nos remite a la idea de algo más abstracto, como es el aspecto institucional: "Institución permanente, sin fines de lucro, al servicio de la sociedad y de su desarrollo y abierta al público, que acopia, conserva, expone, estudia y difunde el patrimonio material e inmaterial de la humanidad con fines de educación, estudio y recreo". Dicho concepto nos deja abierta la idea a muchas posibilidades, siempre que se cumpla con los objetivos relacionados con el patrimonio material e inmaterial.

En nuestro país, la mayoría de la población relaciona al museo con un edificio que atesora objetos arqueológicos u obras de arte, y dentro de estos campos se dieron importantes avances con la construcción de los edificios del Museo Nacional de Antropología “Dr. David J Guzmán” (1999), diseño de los arquitectos Francisco Altschul y Roberto Dada, y del Museo de Arte de El Salvador (2003), diseñado por el arquitecto Salvador Choussy. En ambos casos se cumplió con el deseo generalizado que el país pudiera contar con edificios diseñados para poder exhibir adecuadamente los bienes, ya sean culturales o artísticos, a la vez de satisfacer los requerimientos actuales que demanda una institución de este tipo.

Otros logros en cuanto a la apertura de museos en el país se ha dado con la adecuación de algunos inmuebles con valor cultural de la ciudad capital para ser utilizados con fines museísticos. Tal es el caso del Museo Forma, 
establecido en un inmueble sobreviviente de varias ocupaciones y el Museo Universitario de Antropología, MUA, de la Universidad Tecnológica de El Salvador, para el cual se adecuó una antigua residencia sobre la calle Arce; ambos casos comparten el hecho que se adecuaron inmuebles que originalmente tuvieron un uso habitacional y que fueron diseñados como tales en las primeras décadas del siglo XX.

Fuera de la capital, destaca la adecuación del antiguo edificio del Banco Central de Reserva en la ciudad de Santa Ana para ser utilizado como museo, y que alberga en la actualidad el Museo Regional de Occidente. Fuera de las consideraciones acerca de lo acertado o no de los procesos de adecuación, es importante mencionar que en los casos mencionados se realizaron intervenciones que no atentaron contra los valores culturales de las edificaciones, por lo que al valor de las colecciones que presentan estas instituciones, ya sea en exhibiciones permanentes o temporales, se añade la importancia cultural del edificio que las contiene.

Un museo establecido en un edificio histórico puede ser un valor agregado para el primero, ya que al atractivo que pueden representar las piezas exhibidas se suma el hecho que el visitante pueda reconocer la edificación como una obra arquitectónica significativa. En algunos casos, y dependiendo del tipo de edificio y de su decoración, pueden darse conflictos en cuanto al aspecto museográfico al competir el espacio interno con las obras expuestas, causando que la atención del público se desvíe de las características de estas a las del espacio; tal es el caso que puede darse con el edificio del Palacio Nacional ubicado en el centro de la capital, el cual ha sido considerado para diversos proyectos de futuros museos. Estos problemas en cuanto a la relación del edificio con el material que se debe exhibir pueden ser resueltos con un buen proyecto de adecuación y un acertado diseño museográfico.

Ciertos templos religiosos tienen todas las posibilidades para convertirse en museos - sin perder su función religiosa-, toda vez que cumplan con los requerimientos de educar, conservar y difundir su patrimonio. Los templos coloniales cumplían con la función didáctica de enseñar los misterios de la religión católica a una población que en su mayoría no sabía leer y escribir la lengua española y que no tenía acceso a un libro impreso como la Biblia. De aquí que a sus paredes se adosan retablos que narran historias de la fe a través de pinturas y esculturas. En ellos hay un discurso y una lógica a través de las escenas y de las figuras plasmadas en estas expresiones artísticas. 
La tradición también puede estar ejemplificada, o al menos insinuada, en algunos de estos templos. Algunos de ellos, tal es el caso de la catedral de Sonsonate, no se limitan a mostrar su riqueza escultórica a través de las imágenes religiosas, sino que también presentar algunas de ellas como parte esencial de la dinámica procesional, tan importante y conocida en esta localidad. Estas esculturas, especialmente las pertenecientes a los ritos de Semana Santa, fueron creadas principalmente para procesionar, o sea, para salir a la calle en hombros de los feligreses. Su razón de ser como pieza procesional y como parte de una tradición es ilustrada a través de mostrarlas sobre las andas o plataformas con que se recorre la localidad.

Sin embargo, es de tomar en cuenta que los pocos templos coloniales y del siglo XIX que se conservan en nuestro país no tienen una unidad estilística ni una identificación con un solo período. Estos han sufrido reformas y transformaciones que son producto del paso del tiempo y un reflejo del cambio de gusto en la feligresía, la cual ha patrocinado la fabricación de altares o esculturas que han sustituido a otros más antiguos. En estos casos, es de considerar que en estos edificios, se encuentra también un aspecto cronológico e histórico que debe ser interpretado para el visitante, junto con el desarrollo de un discurso religioso y el artístico-cultural.

A pesar del valor cultural y artístico en varios de los templos católicos del país, hasta la fecha no se ha fundado ningún museo de arte religioso como dependencia anexa a alguno de ellos; sin embargo, un hecho digno de mencionar es el establecimiento de una sala de exhibición de arte sacro al finalizarse el proyecto de restauración del templo Santiago Apóstol de Chalchuapa, la cual pudo llevarse a cabo al estar la comunidad consciente del valor cultural de los bienes de este edificio.

La carencia de un edificio, la presencia de bienes culturales a "cielo abierto" y la acostumbrada evasión a visitar estos lugares con fines de esparcimiento cultural, son causas del porqué no podemos identificar algunos de nuestros cementerios municipales como museos. Sin embargo, al respecto ya se encuentran experiencias exitosas, inclusive en el ámbito de América Latina. Han destacado dentro de estas, los casos recientes de los cementerios San Pedro de Medellín (Colombia) y Presbítero Maestro de Lima (Perú), en los cuales se ha dotado a estos lugares de las facilidades y servicios necesarios de un museo, con visitas guiadas y actividades educativas diseñadas para dar a conocer a los visitantes los valores culturales de la arquitectura y escultura funeraria. 
Cementerios como "Los Ilustres" de San Salvador, "Santa Isabel" de Santa Ana, los cementerios municipales de San Miguel, Santa Tecla, Ahuachapán entre otros, contienen una riqueza en bienes arquitectónicos y escultóricos que debe ser conocida y valorada por la población a través de la formulación y ejecución de planes de manejo, desarrollados con la visión de estos sitios como museos, con la consecuente importancia de la realización de un programa educativo.

Debemos tener presente que los museos no solo tienen una función importante como instrumentos de educación, sino también en cuanto a su papel de agentes propiciadores de una conciencia de identidad cultural que alimente el sentido de pertenencia y responsabilidad colectiva y comunitaria. Estas instituciones refuerzan la identidad y la conciencia de la importancia del patrimonio cultural, es por ello que es necesario fomentar "la cultura de los museos" y a la vez considerar, independientemente de las ideas en torno al museo y su edificio, las posibilidades que tenemos como país para el desarrollo de ciertos inmuebles como museos, conscientes de las consecuencias y retos que conlleva la sostenibilidad y el mantenimiento de una institución de este tipo.

\section{Referentes bibliográficos}

Cinotti, Mia. El Museo del Prado de Madrid. Barcelona: Editorial Noguer S.A.,1973.

Narcía, Elva. El efecto “Guggenheim”, en www.news.bbc.co.uk.

Serullaz, Maurice y Pouillon, Christian. Museo del Louvre. Barcelona: Grupo Editorial Océano, 1996.

Wilson Lloyd, Ann. Museos de arte pierden piso para el arte, en The New York Times, febrero. 2004. 


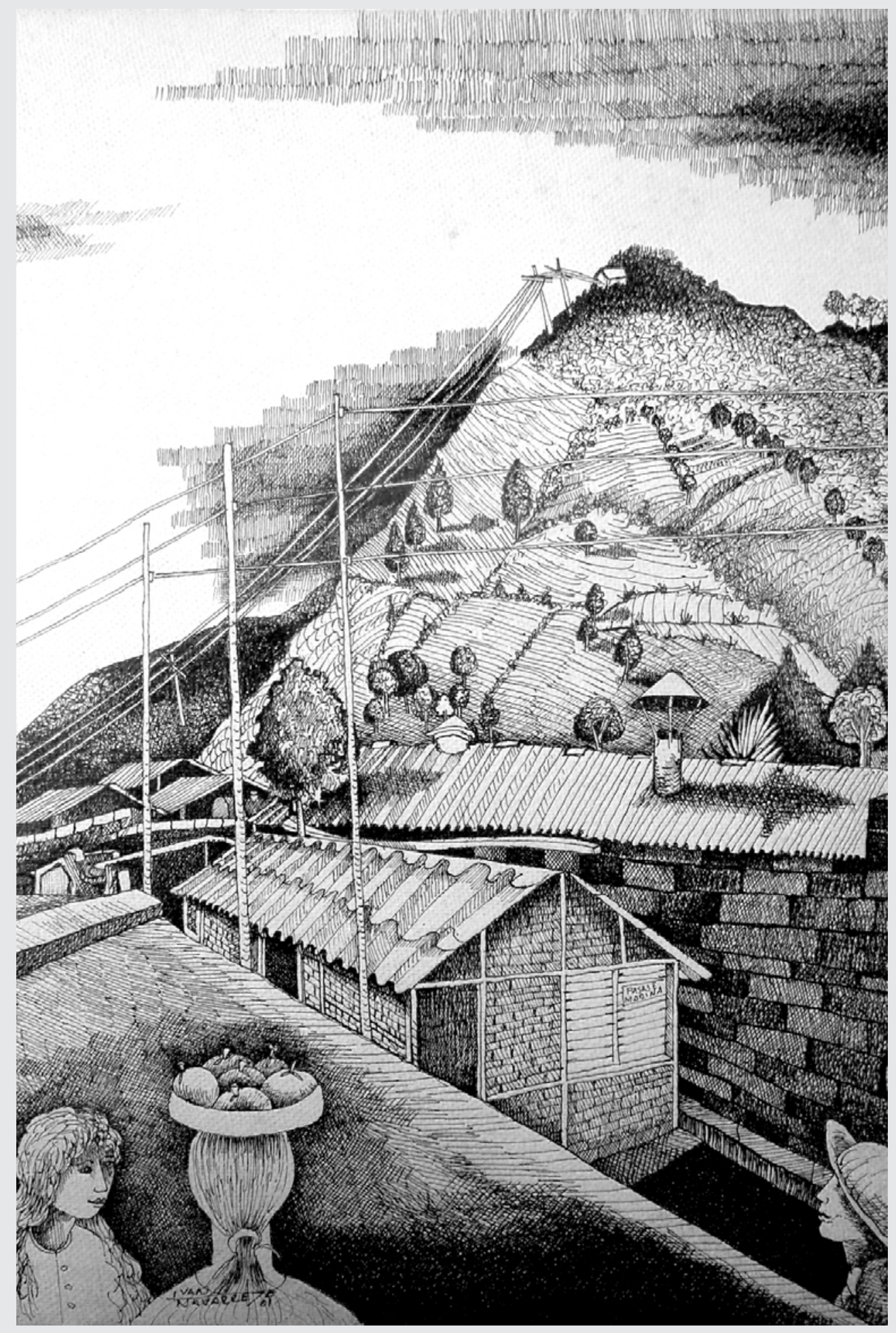

